\title{
THE STRUCTURE AND GROWTH OF THE PLESIOSAURIAN PROPODIAL
}

\author{
ROY L. MOODIE \\ Department of Anatomy, University of Illinois, Chicago \\ SIX TEXT FIGURES AND ONE PLATE
}

Plesiosaurian propodials ${ }^{1}$ presenting unusual characters in the presence of grooves, foramina, cavities and canals have been known to paleontologists for some years and they have been commented on by Williston ('03), Lydekker ('89), Kaprijinoff ('82), Smith Woodward ('98) and the writer ('08).

Since few attempts have yet been made to explain the curious conditions found in the limb bones of plesiosaurs the writer wishes to take this opportunity of offering his views as to the meaning of these structures. The explanation offered below was developed in connection with the study of an immature skeleton of a new plesiosaur described some three years ago (Williston and Moodie '13) in a preliminary way.

That there may be no misunderstanding concerning the use of the word immature, it will be necessary to state that the plesiosaur exhibiting the conditions referred to above simply had not attained its full growth, as is evidenced by the immature conditions of the limb bones, in which the articular

\footnotetext{
${ }^{1}$ The terms propodium, mesopodium and metapodium (which are equivalent to propodial, mesopodial and metapodial) were first used to indicate the separate portions of the molluscan foot as it occurs in the gastropods and pteropods, where it is divided into three distinct parts. The terms are equivalent to the propterygium, mesopterygium and metapterygium of the fishes. Since in the plesiosaurs there is very little structural difference between the skeletal elements of the fore and hind limb, it being impessible to locate isolated bones exceptiby comparison, and since the bones of these animals are so commonly found disassociated, paleontologists felt the need of some term to indicate the limb elements without referring to its location on the body, so the terms propodial, mesopodial and metapodial were adopted. Propodial is the more common term, and indicates a limb bone which is either a femur or a humerus.
} 
surfaces have not developed distinct facettes; the mesopodial elements are rounded and incomplete as though imbedded in a mass of cartilage, as well as the presence of growth characters which, heretofore, have been found only in young or embryonic bones. The species of plesiosaur referred to has been described as Ogmodirus martinii and the animal may have been twelve, to fifteen feet in length, which, in comparison with other members of its family (the Elasmosauridae) is not long. The Plesiosauria included some of the largest aquatic reptiles which have ever existed, equaled perhaps, though not exceeded by some of the extinct crocodiles. The largest known are probably those of the Kansas chalk, or the Jurassic of Wyoming, which probably reached a length of nearly or quite fifty feet, of which the neck formed about one-half (Williston, '14).

The elements of this incomplete skeleton which concern us here are the humerus, the femur and the phalanges. These are the only elongate bones of the limbs, the other elements being rounded plates (text fig. 1). In one of these, the femur, the bone has been broken across the plane of the medullary cavity, exhibiting the internal structure of the bone at this place (plate 1, fig. 3 and text fig. 4). The foramen, which is clearly evident from a lateral view of the bone, leads into an elongate canal, which, in turn, opens into an enlarged medullary cavity, which is filled with calcite in the specimen, and from this cavity the bone structure (plate 1 , fig. 3 ) radiates in all directions. The outlines of the medullary cavity are not regular, but present many sharp pointed indentations which have been interpreted as being the places of exit of the Canales ossificantes perforantes.

The ends of the limb bones are covered with curious pits and cones which resemble miniature volcenoes 'A' (plate 1, figs. 2 and 4). The significance of these curious structures is suggested below. They are confined to immature bones. It has been generally assumed that all of these unusual characters mentioned above have been confined to the propodium, but, in studying the osteology of Ogmodirus it was noted that the phalangeal bones exhibited the foramina, canals and cavities, 
with the same curious development of the articular ends as in the propodium. From what we know in the development of mammalian long bones it would be expected that all long

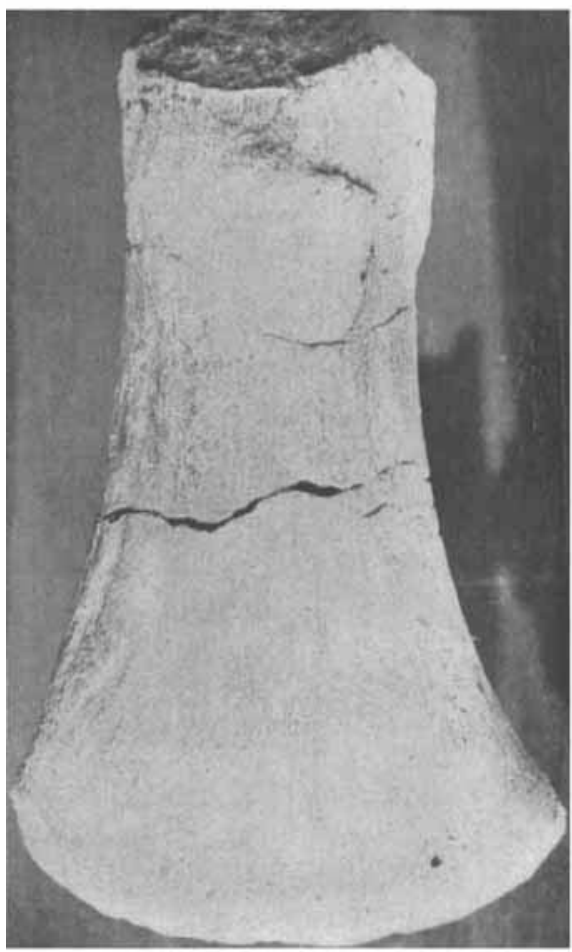

1

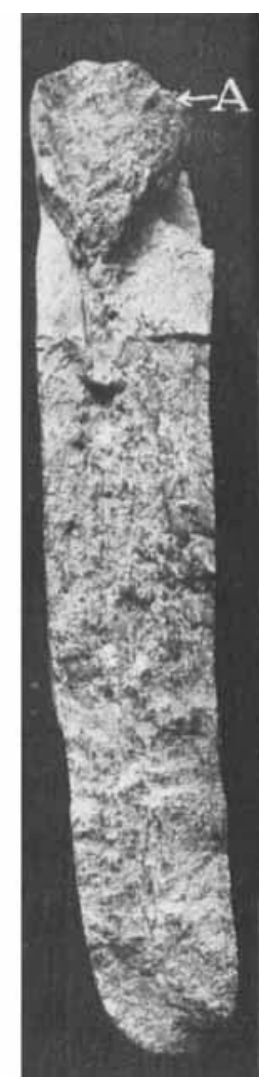

2

Fig. 1. Femur (propodial) of Ogmodirus martinii, Williston and Moodie, from the Cretaceous of Kansas. $X .5$

Fig. 2 A longisection of the distal portion of an embryonic plesiosaurian propodial, showing the sharply marked cone at $A$ indicating a distinct difference in the rate of growth in the peripheral, or perichondral, and the secondary or endochondral bone. The cone-shaped structure $A$ has been called an epiphysis.

bones in the extinct reptiles should exhibit these characters. Further study of this problem will doubtless result in the discovery of these characteristics in all of the plesiosaurian long bones, especially in young and immature animals.

JOURYAL OF MORPHOLOGY VOI. 27, NO. 2 
The writer believes that an adequate explanation of these interesting conditions is to be found in the developmental history of mammalian long bones.

The embryonic characters in developing long bones of mammals are so well known that little need be said here concerning them. Szymonowicz ('02) has figured in a developing long bone of a mammal an opening which he terms 'periosteal bud,' similar in all respects to the opening in the edge of the plesiosaurian propodial. In both cases a canal leads from the foramen into the medullary cavity. A similar observation is recorded in the text-book of histology by Böhm, Davidoff and Huber (p. 117, fig. 85) for a lizard embryo, and showing a much earlier stage in the development of the canal. These observations are readily confirmed on embryonic material; the pig shawing the characters in a well-developed manner.

That this canal and opening persist for some time in foetal life is indicated by Jackson ('04) where he has figured and described a similar but more advanced condition in the tibia of a three day cat. Through the opening in the edge of the bone pass the bloodvessels supplying the medullary cavity, as well as the osteoblasts and the marrow-forming elements. It is very interesting to observe the persistence of this canal and foramen in mammals for that is exactly the condition in the immature plesiosaur referred to above (Ogmodirus martinii) as well as in all embryonic propodials of the plesiosaurs; with the important difference that this embryonic feature was retained much longer in the ancient plesiosaurs than it is in the modern mammals. There is no reason for doubting that the same processes of bone formation went on in Cretaceous times as are going on now, so the comparison is a safe one.

In all, or nearly all, young and embryonic bones of plesiosaurs, which are fairly common in the Cretaceous deposits of Kansas, there occur the above mentioned foramina, canals, cavities, and a well-marked groove, extending, in some cases entirely around the bone, and often persisting until late in life, being known to occur in an adult limb bone of Polycotylus. A representative embryonic propodial is figured herewith (text 
fig. 5), the characters of which have already been fully described (Williston '03 and Moodie '11). In this specimen all of the growth characters above referred to, i.e., canal, foramen, cavity and groove, are present. The groove forms, save for a slight interruption, a shallow smooth-bottomed trough en-
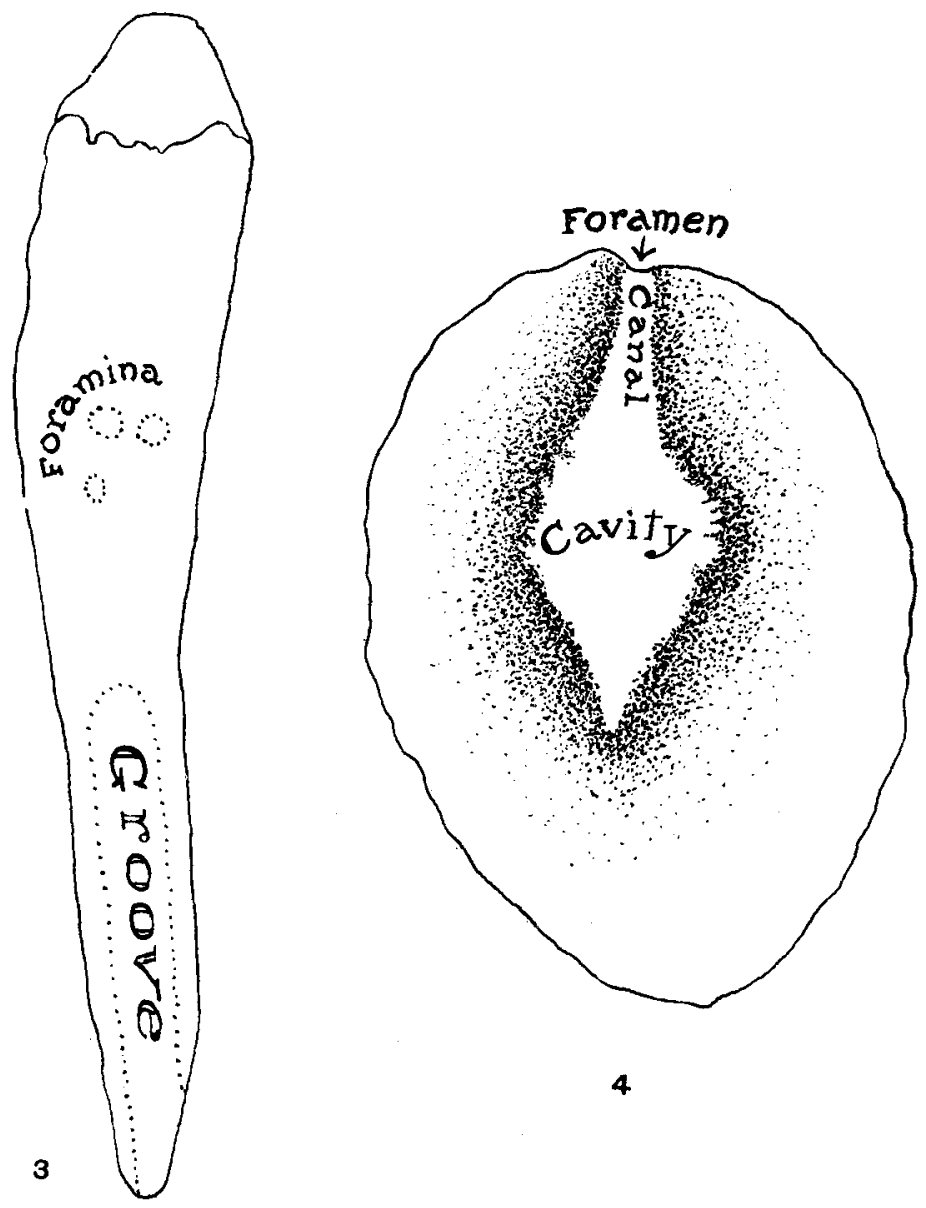

4

Fig. 3 A drawing of the edge of a plesiosaurian (Polycotylus) propodial showing the growth characters in the shape of a groove at the distal end and three foramina which later may have either developed into Volkmann's canals or have disappeared.

Fig. 4 Drawing of the cross-section of the femur (fig. 1) as it is shown in a broken condition in plate 1, figure 3 . The foramen is the same as one of those shown in figure 3. 
tirely around the periphery of the bone. On one side of the bone there are three vascular openings of some size as well as many smaller ones. In adult bones all of the characters disappear, the groove gradually being forced toward the distal end, where it may persist for some time, the cavity, canal and foramen being gradually obliterated.

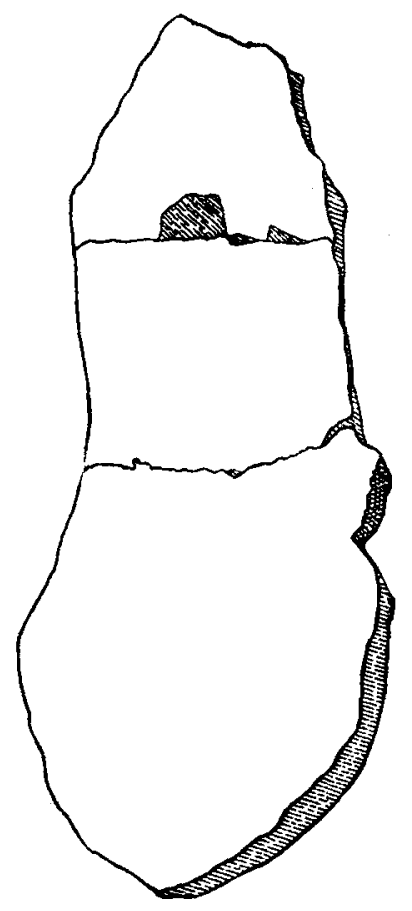

Fig. 5 An embryonic plesiosaurian propodial, from the Cretaceous of Kansas. This bone shows all the growth characters discussed in the present paper. $\times 1$.

The groove on the edge of the bone can only be explained on the assumption that there are two ossific centers for the propodium, and that between the extension of these the cartilaginous endochondrium reaches the edges of the flattened bones. In the bottom of this groove a capillary bud has pierced the perichondral (periosteal) lamella and has invaded the endochondrium, thus forming the 'foramen.' Later piercing of this vessel (periosteal bud) results in the formation of the 'canal' 
and the final invasion and spreading out of the arteries results in the formation of the medullary cavity. From this medullary cavity canals lead out to the extremities of the bone, as will be immediately described.

On the ends of the propodials of the immature Ogmodirus martinii, are well-developed rugosities which take the form of miniature volcanoes. (Plate 1, figs. 2 and 4). They are distributed over the entire articular surface of the bone. These openings and mounds are, doubtless, explained on the basis of bone growth in mammals. Bidder ('06) has offered an interesting explanation for the formation of epiphyses in mammals, by the migrations of the osteoblasts through special vascular canals (Canalis vasculosis perforans) which traverse the space between the medullary cavity and the cartilaginous caps at the ends of the limb bones. This condition is indicated diagrammatically for the plesiosaurs (text fig. 6), which is based on a study of broken and sectioned plesiosaurian limb bones. The periphery of the medullary cavity in the femur of Ogmodirus is very irregular and leading out from the sharp-pointed embayments are the Canales ossificantes perforantes, as is indicated in text figure 6 . The blood vessels, and with them the migrating young mesenchymal cells - the osteoblasts-may have traversed these canals through the previously formed bone to enter the cap of articular cartilage. The action of the boneforming elements was not, in this case, to produce new osseous growths (epiphyses) but simply resulted in the extension in the length of the bone. The mounds on the ends of the propodials look as if bony matter had been poured out of the small opening to harden around the orifice, exactly as lava does around the opening of a volcano. What really happened was that the osteoblasts, if they form bone, arranged themselves on the borders of the openings of the Canales ossificantes perforantes and there formed the bone which resulted in the extension in length.

The limb bones of the plesiosaurs, ichthyosaurs, mosasaurs, and some of the larger dinosaurs are solid, as they are in the modern manatees. This condition is, of course, due to the absence of an osteolytic element (presumably the osteoclasts) or the pres- 
ence of these cells in small and ever diminishing numbers. In explanation of the absence of these cells, or the lack of evidence of their activity we find that only the more sluggish Mesozoic reptiles exhibit solid limb bones. The more active theropodous dinosaurs, the teleosaurs, the crocodiles, turtles and birds have

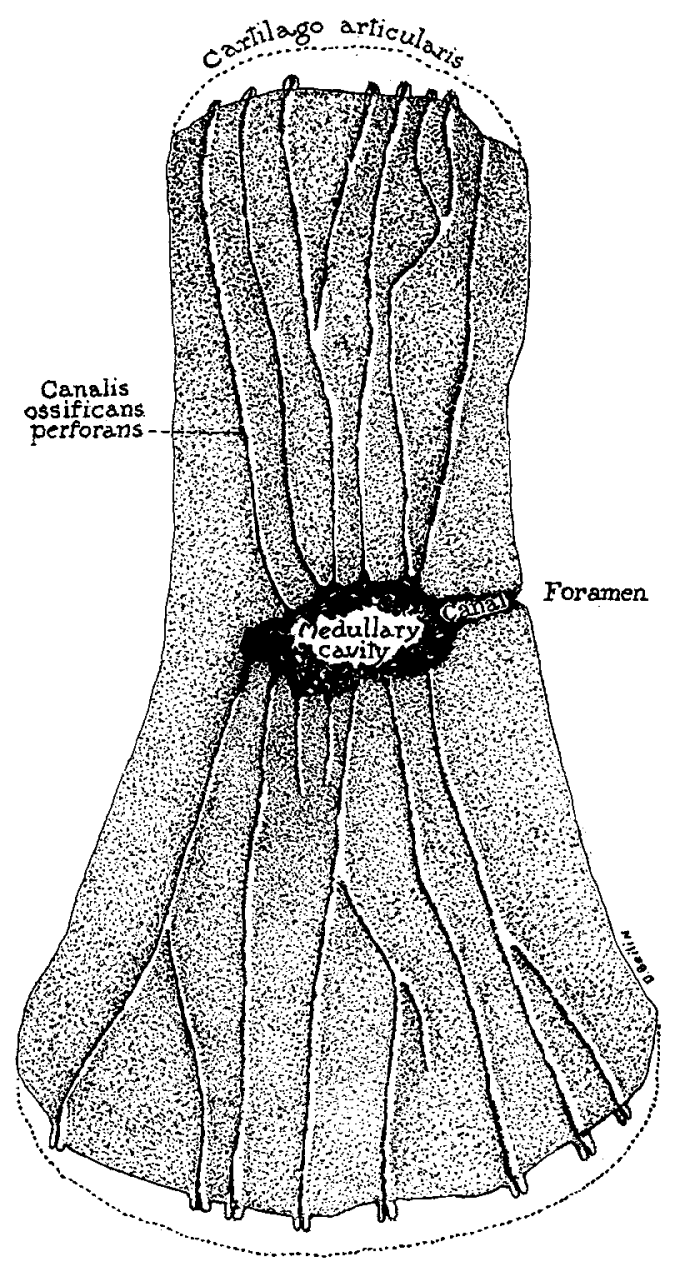

Fig. 6 A diagram based on actual material, showing in a medial section the way in which the various growth characters are associated. The cones, shown at the terminations of the 'Canales ossificantes perforantes' are showr by photograph in plate 1 , figures 2 and 4 . 
hollow limb bones. Why activity should result in the production of osteoclastic or other osteolytic elements is uncertain, but the evidence that such was the case is clear.

From the above discussion it is clear that the growth of bone followed precisely the same lines in ancient Mesozoic times as prevail today. The bone was doubtless preformed in cartilage, though no definite evidence of this is yet available. The osteoblasts arranged themselves first around the periphery and formed the perichondral (primary periosteal) lamella of bone, which was later pierced by a 'periosteal bud,' either at the time of formation of the bone or later by a process of erosion. The osteoblasts doubtless migrated, in the plesiosaurs, as in modern mammals through the opening made by the periosteal bud into the cavity formed in the endochondrium and there formed the secondary bone; which later became pierced by the Canales ossificantes perforantes extending to the ends of the bones. The cavity, canal and foramen later became filled up with bone, owing to the absence of osteolytic elements and resulting in the formation of a solid limb bone. Whether the foramen and canal resulted in the formation of a Volkmann's canal, is uncertain, but, since there are often evidences of more than a single canal, it is quite probable that one or more of these perforating canals through the primary lamella may have formed such a structure.

The growth of primary periosteal (perichondral) and the secondary (endochondral) bone in the plesiosaurs was quite distinct as is evidenced by specimens of embryonic and young bones, in which it is clear that the formation of bone has been produced by growth in different directions, resulting in a sharp cleavage between the layers of bone.

\section{SUMMARY}

Growth characters among the Cretaceous plesiosaurs followed, so far as the limb bones are concerned, essentially the same lines as do mammalian limb bones at the present time. The characters present in immature plesiosaurian propodials can be explained on the basis of embryonic characters of mammals. Solid limb bones, evidently only present in the more sluggish 
and inactive types of reptiles, are probably due to the absence of an osteolytic agent, which, in other animals, produces the medullary cavity of adults. The primary medullary cavity of the plesiosaurs, due to the inroad of the branches of the "periosteal bud' becomes obliterated, as do all other growth characters, i.e., canal, foramen, groove, and rugosities, very late in life, thus furnishing an interesting instance of the persistence, in the Mesozoic reptiles, of characters which at present are found to occur in modern mammalian embryos.

\section{BIBLIOGRAPHY}

Bidder, Alfred 1906 Osteobiologie. Archiv für mikros. Anatomie, Bd. 66. $137-210$.

JACKson, C. M. 1904 Zur Histologie und Histogenese des Knochenmarkes. Archiv für Anat. u. Physiol., Anat. Abth., Jahrg. 1904, p. 33.

Kiprijanoff, W. 1882 Studien über die fossilen Reptilien Russlands. Mem. de l'Acad. Imp. des Sci. de St. Petersburg, VIII Series, pt. II.

Lydekker, Rrchard 1889 Catalogue of the fossil Reptilia and Amphibia, vol, 2, p. 149 .

Moodra, Roy L. 1908 Reptilian epiphyses. Amer. Jour. Anat., vol. 7, no. 4, pp. $443-467$.

1911 Trans. Kans. Acad. Sci., pp. 99-100

Szymonowicz, I. 1902 A text-book of histology and microscopic anatomy of the human body, Trans. by MacCallum, p. 270.

Williston, S. W. 1903 North American Plesiosaurs, Field Museum Publication No. 73, pp. 73-74.

1914 Water reptiles of the past and present, Chicago, p. 88.

Williston, S. W. ANd Moodie, Roy L. 1913 A new plesiosaurian Genus from the Cretaceous of Kansas. Bull. Geol, Soc. America, vol. 24, no. 1, pp. 120-121.

Woodward, Arthur Smith 1898 Vertebrate paleontology, Cambridge, p. 170.

\section{PLATE 1}

\section{EXPLANATION OF FIGURES}

1 Propodial (humerus) of Ogmodirus martinii, Williston and Moodie, from the Cretaceous of Kansas $\times 0.5 ' \mathrm{~S}$ ' $=$ tooth marks of some predaceous fish or reptile of the Cretaceous seas.

2 Distal articular end of the humerus of the Ogmodirus showing ' $A$ ' the details of the small 'volcanoes' the ends of the 'Canales ossificantes perforantes.' $\times 0.75$.

3 Cross-section of the femur (fig. 1) showing the foramen, canal and calcite-filled cavity. The bone structure radiates from the calcite-filled medullary cavity. $\times 1$.

4 Proximal end of the humerus of Ogmodirus, showing growth characters ' $A$ ' in the form of small voleano-like eruptions. $\times 0.75$. 


\section{ROY L. MOODIE}
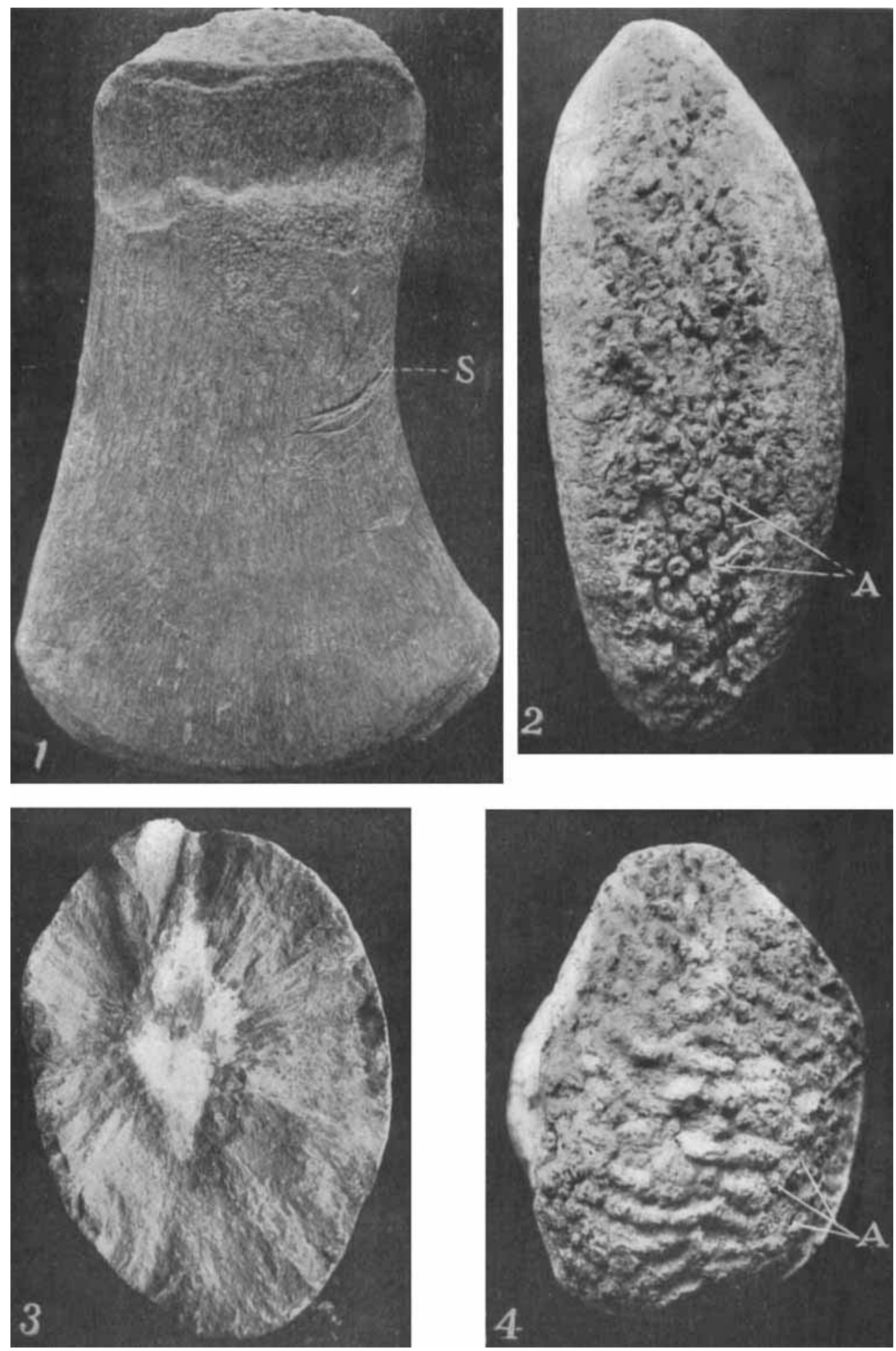